Knowledge gaps among smallholder farmers hinder adoption of conservation biological control

Prisila A. Mkenda*1,2, Patrick A. Ndakidemi ${ }^{1}$, Philip C. Stevenson ${ }^{3,4}$, Sarah E.J. Arnold $^{1,3}$, Iain Darbyshire ${ }^{3}$, Steven R. Belmain ${ }^{3}$, Jan Priebe ${ }^{3}$, Anne C. Johnson², Julie Tumbo5, and Geoff M. Gurr², 6

${ }^{1}$ School of Life Sciences and Bioengineering, The Nelson Mandela African Institution of Science and Technology, PO Box 447, Arusha, Tanzania; ${ }^{2}$ Graham Centre for Agricultural Innovation, Charles Sturt University, PO Box 883, Orange, NSW, 2800, Australia; ${ }^{3}$ Natural Resources Institute, University of Greenwich, Chatham Maritime, Kent ME4 4TB, United Kingdom; ${ }^{4}$ Royal Botanic Gardens, Kew, Richmond Surrey, TW9 3AB, United Kingdom; ${ }^{5}$ CADEM Consultancy, P.O Box 36303, Kigamboni, Dar es Salaam, Tanzania; ${ }^{6}$ Institute of Applied Ecology, Fujian Agriculture and Forestry University, Fuzhou, China.

*Corresponding Author: Prisila A. Mkenda

Street address: Nelson Mandela African Institution of Science and Technology, P.O Box 447, Tengeru, Arusha Tanzania

Email address: mayoprisca@gmail.com 


\title{
Knowledge gaps among smallholder farmers hinder adoption of conservation biological control
}

\begin{abstract}
Conservation biological control uses habitat management to enhance the survival and impact of arthropod natural enemies for pest control. Its advantages are that it relies on native or established invertebrate populations that are adapted to local agricultural ecosystems and conditions. We surveyed 300 farmers in three agro-ecological zones of Kilimanjaro Region, Tanzania to assess farmers' knowledge of natural enemies, insect pests and pesticide use and ways of accessing agricultural information to identify hurdles to the adoption of conservation biological control measures. Data were collected through face to face interviews using questionnaires and pictures and by using a novel voiceresponse mobile phone survey. The farmers surveyed regarded almost all insects as pests, with data analyses revealing that $98.7 \%$ of farmers were completely unaware of natural enemies. After completing a short training course, however, awareness was transformed, with $80 \%$ of farmers recognising beneficial insects and expressing an intention to change farming practices to enhance their survival within the crop. Access to information about synthetic pesticide alternatives was a limiting factor to uptake of biological control measures with $8.7 \%$ of farmers reporting no access to agricultural information, while others were mostly dependent on agricultural officers. These findings identified a severe lack of knowledge among smallholder farmers about beneficial insects which will impact adoption of conservation biological control. We recommend improved access to information and knowledge among the technical officers and the smallholder farmers with direct training on agro-ecological intensification for wider adoption of conservation biological control.
\end{abstract}

Key words: Information accessibility, pest management, ecosystem services, natural enemies, insect pests.

\subsection{Introduction}

Insect pests are a major limiting factor in crop production, leading to up to 50\% yield loss in developing countries (Grzywacz, Stevenson, Mushobozi, Belmain \& Wilson, 2014; 
Mwang'ombe, Thiongo, Olubayo, \& Kiprop, 2007; Shannag and Ababneh, 2007). Currently, the majority of the farmers depend heavily on chemical pesticides to control these pests (Wilson and Tisdell, 2001, Kariathi, Kassim, \& Kimanya, 2016), but potential impacts on the environment and human health are alarming (Amoabeng, Gurr, Gitau, \& Stevenson, 2013; Mahugija, Chibura, \& Lugwisha, 2018; Tosi, Costa, Vesco, Quaglia, \& Guido, 2018). Overuse or misuse of these products can also lead to insecticide resistance developing in the pest, aggravating outbreaks (Lekei, Ngowi, \& London, 2014; Ngowi et al., 2001). This is further exacerbated by non-selective pesticides eliminating natural enemies of crop pests, removing the potential for natural pest regulation.

Insufficient knowledge among farmers is correlated with the farmers' level of education and access to limited knowledge is one of the main factors contributing to continuing reliance on pesticides (Olajide, 2011). Ngowi, Mbise, Ijani, London, \& Ajayi (2007) and Kariathi, Kassim, \& Kimanya (2016) reported that many farming communities in northern Tanzania are not aware of the hazards associated with chemical pesticides while their excessive use is largely due to poor training and knowledge of alternatives. Most farmers cannot read the instructions on application rates or heed safety warnings on pesticide labels which in most cases are written in English. This can result in inappropriate application, leading to increased insecticide resistance and greater pest numbers associated with low numbers of arthropod natural enemies (Ntow, Gijzen, Kelderman, \& Drechsel, 2006; Williamson, Ball, \& Pretty, 2008). In response to insecticide resistance, some farmers mix several pesticides together at increased concentrations, exacerbating their negative effects (Ngowi, Mbise, Ijani, London, \& Ajayi, 2007; Wilson and Tisdell, 2001). These agricultural practices are impacting ecosystem services including natural pest control as well as creating health problems to humans and other non-target organisms.

Conservation biological control (CBC) is an approach to enhance the natural enemies of insect pests that are already present in an area by manipulating the environment and farming practices to maximize their collective impact of pest suppression (Aquilino, Bradley, \& Anthony, 2005; Eilenberg, Hajek, \& Lomer, 2001; Martin, Reineking, Seo, \& Steffan-Dewenter, 2013; Palm, Blanco-Canqui, DeClerck, Gatere, \& Grace, 2014). However, an ecological approach to pest management is knowledge-intense, and thus farmers need to be well informed about management practices and the landscape features that support the population of natural enemies for pest regulation in their farms. Laizer, 
Chacha \& Ndakidemi (2019) found that cultural practices such as intercropping and crop rotation to be the most common farming practices among the smallholder farmers in Moshi rural district, but those practices did not address pest management. In addition, the study found that $77 \%$ of the farmers considered ladybirds and honey bee to be insect pests, showing the need to greatly enhance their knowledge about beneficial insects. Several studies have reported on the need to consider the local knowledge for understanding the complex agricultural issues among the farmers (Nguyen, Seddaiu and Roggero, 2014; Meijer, Catacutan, Ajayi, Sileshi, \& Nieuwenhuis, 2015). Therefore, combining smallholder bean farming practices with ecological pest management options such as $\mathrm{CBC}$ may facilitate knowledge assimilation and adoption for sustainable pest control.

This study focused on the understanding of farmers' knowledge about natural enemies, insect pests and pest control practices in bean production systems in order to identify pest management options available to the farmers and potential barriers to CBC. Access to agricultural information was also investigated, and training provided, to ensure key information was made available to farmers. This study presents both the results of a traditional survey and critically evaluates the use of a mobile phone-based method for data collection.

\subsection{Materials and methods}

\subsection{Study sites}

Sites were located across three agricultural zones in the Kilimanjaro region of northern Tanzania within the Moshi rural district where common bean (Phaseolus vulgaris) is widely cultivated. Three zones were classified based on elevation (Pabst, Kühnel, \& Kuzyakov, 2013). A low zone was defined between $800 \mathrm{~m}$ to $1000 \mathrm{~m}$ asl, a mid zone between $1000 \mathrm{~m}$ to $1500 \mathrm{~m}$ asl, and a high zone between $1500 \mathrm{~m}$ to $1800 \mathrm{~m}$ asl. The maximum and minimum temperature from the data collected using climate loggers (measured under shade and sun) for the low zone is $13.5^{\circ} \mathrm{C}$ and $46.5^{\circ} \mathrm{C}$, the mid zone is $12.5^{\circ} \mathrm{C}$ and $46.5^{\circ} \mathrm{C}$ and the high zone is $7.5^{\circ} \mathrm{C}$ and $37.5^{\circ} \mathrm{C}$, respectively. The high zone receives more rainfall than other zones, and as a result, there is only one bean cropping 
season during the short rains (July to October). Other zones have two bean cropping seasons, during short (July to October) and long rains (March to June). The high zone included Mbahe village $\left(3.23^{\circ} \mathrm{S}, 37.50^{\circ} \mathrm{E}\right)$ which is located in the Marangu West ward. The mid zone encompassed Mieresini village $\left(3.33^{\circ} \mathrm{S}, 37.53^{\circ} \mathrm{E}\right)$ and the low zone Kilimo Makuyuni village $\left(3.40^{\circ} \mathrm{S}, 37.55^{\circ} \mathrm{E}\right)$ in the Makuyuni ward. The major crops cultivated in all zones are maize and beans in small scale subsistence farming systems.

\subsection{Sampling}

Farmers growing beans in the three zones were identified with the help of agricultural extension officers. The sample size formula was used to calculate the sample size as described by Olejnik (1984) and Naing, Winn, \& Rusli (2006), with some minor adjustments to fit the time and budget limits, where 100 farmers among all bean growers in the area were randomly selected from within each elevation zone.

\subsection{Data collection}

Before the interview, farmers were informed on the aims of the research and agreed to participate in the study. All research ethics were obeyed including the confidentiality of the names of the respondents during data analysis and reporting. Two methods were used to collect data, face to face interview using questionnaires (Supplementary S1) and an interactive voice response (IVR) survey platform (Chancellor, Priebe \& Mkenda, 2019). The IVR survey was used to evaluate whether smallholder farmers in sub-Saharan Africa have the interest and capacity to utilize the IVR services. Similar information for some measures were gathered from the two methodologies. Farmers were interviewed using structured questionnaires with both closed- and open-ended questions. The researcher made use of enumerators who were trained and able to speak local language in administering the questionnaires.

Farmers' awareness of natural enemies was tested by a closed ended question where they were required to respond by either "YES" or "NO". Their knowledge on the identification of the natural enemies and insect pests was assessed using pictures of an adult individual insect (Supplementary S2) of the following: hoverfly (Diptera: Syrphidae - using Episyrphus spp.), lady beetle (Coleoptera: Coccinellidae - using the lunate lady beetle Cheilomenes lunata) and long legged fly (Diptera: Dolichopodidae - using Condylostylus spp.) as natural enemies and aphid (Hemiptera: Aphididae - using Aphis spp.), blister beetle (Coleoptera: Meloidae - using Mylabris phalerata), and caterpillar (Lepidoptera: 
Crambidae - using Maruca vitrata) as insect pests, presented as A4 printouts of highresolution photographs, accompanied by a silhouette image indicating actual size. Farmers were asked to state whether they have seen such insects in their fields, the name of the insects (in their local language), and their importance in agriculture.

The IVR data collection involved recording the questions (Supplementary S3) in the local language of the region (Kiswahili) and uploading the recordings in to the mobile system. Pre-trials and training for the IVR system was done through farmer meetings in all zones where farmers were directed on how the voice-response system worked. A sample of 112 among the 300 farmers attended the meeting where 90 of those attended agreed to participate in the actual IVR survey. The survey comprised a subset of questions that were asked during the face to face interview which focused on insects (both beneficial and pests) observed in their field and pest control methods deployed during the past week, as well as accessibility of agricultural information. The farmers proposed a day and time at which the calls would be made automatically every week throughout the bean cropping season (July to September, 2016). Farmers were asked to inspect their fields every week before the calling day in order to be able to respond to the questions, especially about insect abundance. The farmers' responses were recorded directly into the mobile system as they were talking through the phones or by pressing buttons on phone keypads as instructed. The recorded responses were then translated into English before analysis.

Pre training survey suggested a need to train the farmers on the major insect taxa that occurred in bean fields and their agricultural relevance. Three training stations, one in each elevation zone, were selected with the help of the agricultural officers. All the farmers who were involved in the baseline survey (100 farmers in each zone) gathered at their respective training stations for the training events. The training was conducted one year after the baseline survey, during March to April 2017. Several insect species (pictures and live insects collected from their farms) including those which were shown during the pre-training survey were used in the training. Different pest management techniques including the importance of some field margin vegetation in supporting natural enemy populations were also part of the training. The training aimed at increasing the farmers' knowledge about natural enemies, insect pests and pesticide use, as well as about good farming practices that will enhance the survival of beneficial insects while reducing the insect pests in their farms. Four months after the training, farmers were 
assessed on their knowledge change about insect identification using the same insect species that were shown during the baseline survey. They were also assessed on their interest to different types of pesticides to find out possible changes in pest management techniques.

\subsection{Data analysis}

Statistical data analysis was conducted using the R program (R Core Team, 2017), version 3.5.1. Independent variables were elevation zone, age, sex and education level. The dependent variables were the responses from farmers about accessibility of agricultural information, awareness about natural enemies, identification of insects, pesticide use practices and suggested ways to improve bean production. Chi square test (denoted as $\chi^{2}$ ) was used to test for differences between categorical variables using package FunChisq. The significance level was set at $\mathrm{p} \leq 0.05$ and the degrees of freedom denoted by $\mathrm{df}$.

\subsection{Results}

\subsection{Participant characteristics}

Farmers involved in the study were 39.3\% (118) men and 60.7\% (182) women (Table 1), showing a greater number of women compared with men participate in agriculture in the overall study area. Men and women participation in crop production was significantly different among the three zones $\left(\chi^{2}=24.837\right.$, df $\left.=2, p<0.001\right)$, with men percent increasing from the low zone (20\%) to the mid zone (45\%) and to the high zone $(53 \%)$, while women were more in the low zone (44\%), decreasing to $30 \%$ in mid zone and only $26 \%$ in the high zone. There was also a significant difference among the farmers in terms of age and gender $\left(\chi^{2}=12.091, \mathrm{df}=2, \mathrm{p}=0.002\right)$. The participation of women within age groups: 18 to 35 years, 36 to 45 years and above 45 years was $35.7 \%, 34.1 \%$ and $30.2 \%$, respectively, showing a slight decrease in farming with increasing age but broadly speaking that farmers surveyed were evenly representative of ages groups. However, the same age groups for men was $23.7 \%, 26.3 \%$ and $50.0 \%$, respectively, showing lower participation of younger men in agriculture.

Education level of the farmers among the three zones differed $\left(\chi^{2}=18.143\right.$, $\mathrm{df}=6, \mathrm{p}=$ 0.006). Farmers with incomplete primary education were more abundant in the low zone $(10.0 \%)$, followed by the high zone $(4.0 \%)$ and only $2.0 \%$ in the mid zone. Only three 
farmers had attained further vocational education, all from the mid zone (Table 1). Overall, significant differences in farmers' age and education were apparent, $\left(\chi^{2}=21.258\right.$, $\mathrm{df}=6, \mathrm{p}=0.001$ ) with no farmers between ages 18 and 35 who had incomplete primary education in any zone, while there were 13 farmers with incomplete primary education at the age of above 45 years, suggesting the dropout from primary school was among younger farmers. There was no significant sex difference $\left(\chi^{2}=2.201, \mathrm{df}=3, \mathrm{p}=0.532\right)$ in terms of education. The major economic activity recorded was farming, with $100.0 \%$ in low zone and $95.0 \%$ in mid and high zones. Other business activities included shoe making, tailoring and carpentry.

\section{Table 1}

\subsection{Participation of farmers in the interactive voice response (IVR) survey}

On average $70.4 \%$ of farmers responded to the call each week. More farmers from the low zone were recruited compared to other zones as a result of their attendance to the trial meeting and willingness to participate in the survey. Although a good number of farmers participated each week, the number of respondents to the different questions varied, where closed questions (which farmers were choosing from given options) were more often responded than open ended questions (which farmers were supposed to answer from their experience or after field observation). Of the two methodologies (face to face interview vs. IVR survey) of data collection used in this study, face to face interview was the most useful as the majority of farmers in the IVR survey did not respond to all questions, whilst some farmers did not answer calls as had been agreed.

\subsection{Farmer awareness of natural enemies and insect pests before training}

Overall, $98.7 \%$ of respondents in the baseline survey were unaware of the existence of natural enemies of pests. The majority of farmers were not able to distinguish natural enemies from insect pests, even lady beetles, hoverflies and long legged flies (Figure 1a) despite these natural enemies being abundant in their fields (PM, personal observation). Most farmers did not recognize the insects at all and returned a "don't know" response, or else provided an incorrect identification. Many farmers were confused between the lady beetle (the adults and larvae of which predate upon aphids) and Ootheca spp. (Coleoptera: Chrysomelidae) (a folivore) considering both to be pests. Farmers differed 
in their identification expertise between zones for lady beetles $\left(\chi^{2}=19.614\right.$, df $=4, p<$ $0.001)$, long legged flies $\left(\chi^{2}=12.072, \mathrm{df}=4, \mathrm{p}=0.017\right)$ and hoverflies $\left(\chi^{2}=19.281, \mathrm{df}=\right.$ $4, p<0.001)$ where farmers from the high zone were the least accurate in identifying the insects compared with other zones (Figure 1a). Farmers' education level had no significant influence in the identification of lady beetles $\left(\chi^{2}=10.892, \mathrm{df}=6, \mathrm{p}=0.092\right)$, long legged flies $\left(\chi^{2}=4.449, \mathrm{df}=6, \mathrm{p}=0.616\right)$ and hoverflies $\left(\chi^{2}=4.274, \mathrm{df}=6, \mathrm{p}=\right.$ 0.640). Similarly, there was no significant difference in the identification of lady beetles $\left(\chi^{2}=0.289, \mathrm{df}=2, \mathrm{p}=0.866\right)$ and long legged flies $\left(\chi^{2}=2.654, \mathrm{df}=2, \mathrm{p}=0.265\right)$ between men and women but only for hoverflies $\left(\chi^{2}=12.739, \mathrm{df}=2, \mathrm{p}=0.002\right)$ where women were the most accurate. From the IVR survey, only 3\% of farmers were able to mention the lady beetle as being a beneficial insect.

The pre-training results showed that the farmers in the three zones were more aware of insect pests than of natural enemies. When shown insect pests in pictures, $53.3 \%$ of the farmers were able to identify aphids (Aphis spp.), 37.7\% caterpillars (including Maruca and Helicoverpa spp.) and $11.3 \%$ blister beetles (Mylabris oculata) (Figure 1b). Blister beetles are among the most apparent insect pests in the area (personal observation) being large and brightly coloured and mostly feeds on flowers, thus occasionally reducing yields, but the majority of farmers were not aware of them as an insect pest.

Awareness of the insect pests (aphids, caterpillar and blister beetle) differed between zones (aphid: $\chi^{2}=37.414, \mathrm{df}=4, \mathrm{p}<0.001$; caterpillar: $\chi^{2}=7.456, \mathrm{df}=4, \mathrm{p}=0.114$, ns; blister beetle: $\chi^{2}=30.939, \mathrm{df}=4, \mathrm{p}<0.001$ ), with farmers in the high zone recognising aphids most accurately, and farmers in the low zone being least accurate, while farmers in the mid zone were most accurate at recognising blister beetles, followed by high zone farmers; again, low zone farmers were least accurate (Figure 1b). However, education level of the farmers had no significant influence on the identification of aphids $\left(\chi^{2}=4.621\right.$, $\mathrm{df}=6, \mathrm{p}=0.593)$, caterpillars $\left(\chi^{2}=7.635, \mathrm{df}=6, \mathrm{p}=0.266\right)$, or blister beetles $\left(\chi^{2}=7.141\right.$, $\mathrm{df}=6, \mathrm{p}=0.308)$. The identification expertise did not differ between men and women for aphids $\left(\chi^{2}=1.795, \mathrm{df}=2, \mathrm{p}=0.407\right)$ and caterpillars $\left(\chi^{2}=3.232, \mathrm{df}=2, \mathrm{p}=0.199\right)$ but only for blister beetles $\left(\chi^{2}=11.237, \mathrm{df}=2, \mathrm{p}=0.004\right)$ where women were more accurate than men.

\subsection{Farmer awareness of natural enemies and their insect pests after training}


Farmers' awareness of natural enemies increased from $1.3 \%$ in the baseline survey to $80.0 \%$ after the training. Farmers were able to identify the same insect taxa (both natural enemies and insect pests) which were given during the baseline survey (Figure 1a and 1b). There was no significant difference in the identification of lady beetles between the zones $\left(\chi^{2}=8.313, \mathrm{df}=4, \mathrm{p}=0.081\right)$, but only for hoverflies $\left(\chi^{2}=40.444, \mathrm{df}=4, \mathrm{p}<\right.$ $0.001)$ and long legged flies $\left(\chi^{2}=32.648, \mathrm{df}=4, \mathrm{p}<0.001\right)$, where more farmers from the mid zone were able to identify both insects as compared with the other two zones (Figure 1a). There was no significant difference in the identification of aphids between the zones $\left(\chi^{2}=2.143, \mathrm{df}=6, \mathrm{p}=0.268\right)$, but only for caterpillars $\left(\chi^{2}=300.12, \mathrm{df}=6, \mathrm{p}<0.001\right.$ and blister beetles $\left(\chi^{2}=300.76\right.$, df $\left.=6, \mathrm{p}<0.001\right)$ where more farmers from the mid zone correctly identified caterpillars and blister beetles compared with the other zones.

\section{Figure 1a}

\section{Figure 1b}

Since most of the farmers were not familiar with natural enemies during pre-training survey, they were not able to state their economic importance or agricultural relevance. Most of the farmers were unaware of the functions of natural enemies while others identified them as pests (Figure 2a). From the four given categories; natural enemy, insect pest, pollinator and unknown, some farmers were able to identify the images of natural enemies as pests of their fields, while others were completely unaware, a few regarded them as pollinators (Figure 2b). However, after the training most of the farmers were able to state the relevance of the insects in their field (figure $2 a$ and $2 b$ ). About $69 \%$ of the farmers were able to state the economic importance of hoverflies as a natural enemy $(16.7 \%)$, as a pollinator $(22 \%)$ and as both a natural enemy and a pollinator $(30.3 \%)$.

\section{Figure 2a}

\section{Figure 2b}




\subsection{Pest management practices and challenges}

\subsubsection{Major insect pests}

The most damaging insect pests according to $78.3 \%$ of farmers were aphids. Other reported insect pests included whitefly (Hemiptera: Aleyrodidae), thrips (Thysanoptera: Thripidae) and bean stem maggot/bean fly (Diptera: Agromyzidae), but they were only mentioned by the farmers in low and mid elevation zones (Figure 3).. Ootheca (Coleoptera: Chrysomelidae) were very common in low zone while caterpillar were more pronounced in the high elevation zone. Fungal diseases and bruchid beetles (Coleoptera: Chrysomelidae) were mentioned only in the high zone.

\section{Figure 3}

\subsubsection{Pesticide use}

Types of pesticides reported by farmers differed between the three zones $\left(\chi^{2}=195.050\right.$, $\mathrm{df}=6, \mathrm{p}<0.001)$. Generally, synthetic pesticides were more commonly used compared to other pest management techniques (Figure 4). About $52 \%$ of the farmers in the high zone did not use any pesticides, whereas $41 \%$ used traditional pesticide materials such as botanicals, ash, cow dung and urine to manage the insect pests. In the low and mid zones, farmers mostly used synthetic pesticides ( $86.0 \%$ and $92.0 \%$, respectively).

Pesticide application frequency also differed significantly $\left(\chi^{2}=148, \mathrm{df}=8, \mathrm{p}<0.001\right)$ among the three zones. On average, the application frequency was more than two times per season for low and mid elevation zones and less than 1 per season in the high zone.

\section{Figure 4}

\subsubsection{Pesticide use by farmers before and after training}

Before training farmers generally reported that they would be inclined to use synthetic pesticides but after the training most of them proposed to use non-synthetic approaches 
such as pesticidal plants which have lower impacts on natural enemies. There was a significant difference in the pesticide recommended for use between the zones before $\left(\chi^{2}\right.$ $=34.478, \mathrm{df}=6, \mathrm{p}<0.001)$ and after the training $\left(\chi^{2}=32.526, \mathrm{df}=6, \mathrm{p}<0.001\right)$. Many farmers from low and mid zones reported that they used synthetic pesticides to manage insect pests both before (19.3\% and $17.3 \%$, respectively) and after (8.0\% and $4.3 \%$, respectively) the training event, compared with the high zone where only $8.3 \%$ before, and $0.3 \%$ after being trained reported that they would use synthetic pesticides (Supplementary S4). The percent of farmers who were unsure about which approach to use before the training increased after the training in low and mid zones, while it decreased in high zone.

\section{Supplementary S4}

\subsubsection{Perceived disadvantages of synthetic pesticide use}

Farmers mentioned various disadvantages/challenges in the use of synthetic pesticides, and those disadvantages differed significantly between zones $\left(\chi^{2}=55.679, \mathrm{df}=12, \mathrm{p}<\right.$ $0.001)$, but with no significant difference between men and women $\left(\chi^{2}=6.843, \mathrm{df}=6, \mathrm{p}\right.$ $=0.336$ ). Most of the disadvantages such as health problems, cost of buying pesticides, pest resistance and language problems (as most packaging is in English) were frequently mentioned in mid and low zones compared with high zone where most of the farmers were not using the synthetic pesticides, thus not experiencing the challenges (Figure 5).

\section{Figure 5}

\subsubsection{Health problems associated with the use of synthetic pesticides}

Overall 58\% of farmers reported to have experienced health problems that they attributed the use of synthetic pesticides. Those most frequently mentioned in all the three zones were eye irritation, flu, skin, chest problems and headache (Figure 6). Experience of pesticide-attributed health problems were significantly $\left(\chi^{2}=16.051, \mathrm{df}=6, \mathrm{p}=0.013\right)$ more pronounced by women (118 out 182) compared with men (56 out 118). In addition, farmers were also assessed on whether they use personal protective equipment during chemical pesticides application. The results show that despite the health issues reported among the users of synthetic pesticide, the majority of the farmers do not use any 
protective equipment during pesticide application, and there was no significant difference between zones $\left(\chi^{2}=5.890, \mathrm{df}=2, \mathrm{p}=0.053\right)$, age groups $\left(\chi^{2}=2.378, \mathrm{df}=2, \mathrm{p}=0.305\right)$ or sexes $\left(\chi^{2}=1.415, \mathrm{df}=1, \mathrm{p}=0.234\right)$. In the high zone, most of the farmers had not applied synthetic pesticides, thus were not using personal protection. Comparison between pesticide use types versus the use of protective gear showed a significant difference $\left(\chi^{2}=30.423\right.$, df $\left.=3, p<0.001\right)$ where most of the farmers applied synthetic pesticides without using any protective equipment.

\section{Figure 6}

\subsection{Access to agricultural knowledge and information}

\subsubsection{Information sources}

From face-to-face surveys, the major resource used by farmers to access agricultural information included agricultural officers (60.4\%), researchers $(30.5 \%)$, and radio $(19.5 \%)$. Across all zones, $8.7 \%$ of farmers reported no access to agricultural knowledge and information. Similar findings were obtained from the IVR survey where agricultural officers were ranked first $(41.7 \%)$, followed by researchers $(30.6 \%)$, then fellow farmers and farmer groups $(22.2 \%)$ and radio (5.5\%). Pesticide vendors were also mentioned as among the sources of information to farmers because they provided information on the type of pesticide to buy in managing certain infestation when the farmers visit their shops.

For increasing effective communication, $53.0 \%$ of farmers proposed more ways of accessing agricultural knowledge and information in addition to those which were currently used (agricultural officers, researchers and radio). The most mentioned additional information sources from the interview were seminars or meetings and mobile phones (Table 2). From the IVR results, the use of mobile phones as an information source was proposed by the majority of farmers compared with other information sources.

\section{Table 2}


Farmers were asked if they had attended formal agricultural training and the results show more than $70.0 \%$ of farmers in all the three zones had never attended any training related to agriculture. Only $24.0 \%$ in the low zone, $26.0 \%$ in mid zone and $31.0 \%$ in the high zone had attended an agricultural training event. The results showed no significant difference between farmers in the three zones $\left(\chi^{2}=1.684, \mathrm{df}=2, \mathrm{p}=0.431\right)$, education level $\left(\chi^{2}=4.747, \mathrm{df}=3, \mathrm{p}=0.191\right)$ or between men and women $\left(\chi^{2}=0.919, \mathrm{df}=1, \mathrm{p}=\right.$ 0.338) in their likelihood of having attended a training course. The kinds of training attended by some of the farmers in the study sites were related to organic farming methods, agribusiness, bean production, as well as production of other crops such as maize, vegetables, pigeon pea and coffee. The major providers of such training events were agricultural officers, governmental institutions (Kilacha, Selian Agricultural Research Institute (SARI) and Tanzania Coffee Research Institute (TACRI)), nongovernmental organizations such as SEVIA (Seeds of Expertise for the Vegetable Sector of Africa) and TAHA (Tanzania Horticultural Association), together with some researchers who were doing research in their area.

\subsubsection{Agricultural knowledge needs}

When farmers were asked what information and training topics they would like to receive, the most commonly mentioned topic was farming methods (53.7\%), followed by pest and disease control (21.7\%), general agricultural education (9.2\%), market information (6.8\%), inputs use (5.6\%) and climate/weather conditions $(2.1 \%)$. A similar trend was observed from the IVR results (Table 3 ). With respect to farming methods, the farmers were specifically interested in receiving more information about bean production together with production of other crops such as maize and vegetables, good agricultural practices, modern agriculture and organic farming methods. In terms of pest and disease control, the major focus was knowledge of various bean pests, pesticide use and various ways of managing pests in the field. Their major concern about climate or weather conditions was knowledge of seasonal timing such as planting as well as information on the amount of rainfall and kind of crops to plant. Knowledge and information required about inputs were typically about good seeds and fertilizers. However, some farmers were interested in receiving general agricultural knowledge and market linkages to increase their income.

\section{Table 3}




\subsection{Farmer advice for improving bean production}

Farmers' suggestions on strategies to improve bean production were significantly different $\left(\chi^{2}=50.828, \mathrm{df}=22, \mathrm{p}<0.001\right)$ among zones. Provision of drought resistant seed varieties, establishment of irrigation systems and provision of loans were only mentioned by the farmers from the low and mid elevation zones while provision of quality and high yield varieties, use of local pesticide materials and soil examination was mentioned by the farmers from the high zone only (Table 4).

\section{Table 4}

\subsection{Discussion}

The study found that the majority of farmers were not aware of natural enemies and the role they play in agriculture, and they consider most of the insects seen in their field as pests. These results support the finding that biological control is poorly applied in most sub-Saharan African countries (Wyckhuys et al., 2013). The reason for such poor applicability is associated with poor knowledge about natural pest control, indicating the need to bridge the gap that exists between research institutions and smallholder farmers. Pest management through $\mathrm{CBC}$ will reduce the cost of production by smallholder farmers who usually have poor access to external inputs. Mkenda, Ndakidemi, \& Mbega (2017) reported the need to identify innovative and acceptable ways of integrating biodiversity in food production systems for sustainable agriculture with emphasis on CBC.

The farmers were initially not able to distinguish between lady beetle (Coleoptera: Coccinellidae) and Ootheca spp. (Coleoptera: Chrysomelidae) and they considered both of them to be insect pests. In addition, they were also not able to identify the blister beetle as an insect pest which mostly feed on flowers. The reason for farmers not connecting the pest with its damage may be due to the fact that blister beetles feed on the flowers and may be confused with pollinators. This agrees with Banjo, Lawal, Fapojuwo, \& Songonuga (2003) and Blodgett, Denke, \& Knerr (2010) who found the blister beetles were not considered as a serious pest despite being found infesting several crops, and causing considerable damage. This is also revealed by Lebesa et al., (2012) who reported 
that majority of farmers did not employ any control measures against blister beetle infesting various crops due to poor knowledge of the pest. Aphids were reported to be the most damaging insect pest by the farmers in all the three zones. This concurs with published literature for this crop in Africa (Abate and Ampofo, 1996).

Farmers' knowledge about natural enemies, insect pests and pest management practices increased significantly after being trained, indicating the need to educate the farmers about good farming practices. The use of synthetic pesticides by such communities is widely reported as the most common practice (Halimatunsadiah, Mazlan, Omar, \& Kamarulzaman, 2016; Ngowi, Mbise, Ijani, London, \& Ajayi, 2007; Williamson et al., 2008). The dependence on synthetic pesticides may be partly due to farmers' lack of knowledge of other pest management options (especially biological control) together with lack of awareness on the impacts of the pesticides on potentially beneficial non-target organisms such as natural enemies of pests. This was realized after the training where the majority of the farmers recommended the use of non-synthetic pesticides rather than the synthetic pesticides. However, there is a need for continuous monitoring of the implementation of what they recommended especially after the training, to avoid any social desirability that may exist. Pesticide application frequency was found to be more than two times per season for low and mid zones, indicating high pesticide use rates. A similar study in Tanzania by Ngowi, Mbise, Ijani, London, \& Ajayi (2007) found pesticide applications to be up to 5 times per cropping season, with $53 \%$ of the farmers reporting an increasing trend in pesticide use. Education offers scope to liberate the farmers from their current farming practices that rely too much use of agrochemicals which are hazardous to health and the environment. According to Kremen and Miles (2012) sustainability in agriculture requires farming practices that are less dependent to external inputs.

The differences in farm size in the three zones (Mkenda et al., 2019) may influence the type of pesticide use. The size of the farms in low and mid zones are large compared with the farms in the high zone, therefore the availability of plant based pesticides may be insufficient to apply to larger farm sizes in low and mid zones, hence promoting the use of synthetic pesticides. CBC can more easily be adopted by the farmers in the high zone where the fields are relatively small and have less use of synthetic pesticides than in low and mid elevation zones. Climate may also influence the adoption of $\mathrm{CBC}$ in the three zones due to differences in vegetation cover along the elevation gradient of Mt. 
Kilimanjaro (Hemp, 2006). There is sufficient vegetation cover which may effectively enhance $\mathrm{CBC}$ throughout the year in the high zone, as compared with low and mid elevation zones, due to differences in the amount of rainfall and temperature (Mulangu \& Kraybill, 2013). However, habitat management such as promotion of field margin vegetation in low and mid elevation zones may provide food and refuge to natural enemies of insect pests especially during the off-season when the bean fields remain almost bare after harvest.

Several studies have reported increased chemical pesticide use as a result of increased insecticide resistance, planting of crop varieties that are highly susceptible to pests, ineffective pesticides, market growth in 'discount' and often unauthorized pesticides, subsidy and donations and lack of attention to the economics of pest management (Williamson et al., 2008). It is further reported an increased pest infestation with decreased beneficial insects in the fields as a result of misuse and/or overuse of synthetic pesticides (Belmain, Haggar, Holt, \& Stevenson, 2013; Heitala-Koivu, Lankoski, \& Tarmi, 2004; Landis, Wratten, \& Gurr, 2000; Wyckhuys et al., 2013). In contrast, botanical pesticides experiments conducted in the area (Mkenda et al., 2015; Mkindi et al., 2017) have reported to be less harmful to non-target organisms, hence important in enhancing $\mathrm{CBC}$. These results call for further research on the feasibility of $\mathrm{CBC}$ within the smallholder bean farming systems.

Various challenges in the use of synthetic pesticides such as health problems, cost of buying pesticides, pest resistance and language problems (as most packaging is in English) were mentioned by the farmers in low and mid zones where the majority of them are synthetic pesticide users. Similar findings about the challenges of pesticide use were also reported by Ngowi, Mbise, Ijani, London, \& Ajayi (2007) and Ntow et al. (2006). The most frequently reported negative perception of pesticide use was health problems, which was usually associated with incorrect pesticide use. Similar results have been reported by Ashburner and Friedrich (2001); Matthews, Wiles, \& Baleguel (2003) and Sibanda, Dobson, Cooper, Manyangarirwa, \& Chiimba, (2000) as a common problem in African countries. Common misuse practices include the use of inappropriate products, incorrect dosage, leaking application equipment, use of mixes of several pesticides, tongue testing of concentration and non-use of protective equipment such as face masks, gloves and shoes. This is manifested in the present study in which the majority of the farmers declared that they do not use any protective equipment during pesticide 
application. This is further supported by Amoabeng et al. (2017) who reported that 77\% of the farmers surveyed were not using protective gear during synthetic pesticide application. Although the health of the farmers is clearly affected by misuse of synthetic pesticides, farmers usually do not report the symptoms to local health centres and are unlikely to understand longer term chronic effects of exposure. According to Margni, Rossier, Crettaz, \& Jolliet (2002) most of the health problems associated with synthetic pesticides use are neurological and may not be easily recognized by the medical community due to the fact that pesticides consist of active ingredients as well as inactive ingredients which are difficult to identify. Farmers need to be given all the appropriate information on the negative effects associated with the use of chemical pesticides as well as alternative eco-friendly methods of managing pests.

Many farmers identified that they lacked important agricultural knowledge and information which could help them in making an informed decision in their day to day agricultural practices, due to the limited number of information distribution sources. While agricultural officers were found to be the major source of information, many farmers were not satisfied with their service because of inadequate frequency of interaction owing to few officers to cover all areas. A study by Adhiguru, Birthal, \& Kumar (2009) and Ronald, Dulle, \& Honesta (2014) also found most of the smallholder and marginal farmers had poor access to agricultural knowledge and information due to insufficient availability of information sources available. Aina (2006) reported that some farmers were unable to access agronomic information and may even go for five years without coming into contact with extension officers. A major concern by farmers was the need for government to increase the number of agricultural officers so that they could have access to better knowledge and information and more frequently. This concurs with other studies conducted in Tanzania by Adam, Sindi, \& Badstue (2015); Aina (2006); Elly and Silayo (2013); Mtega, Ngoepe, \& Dube (2016); Siyao (2012) and Lwoga, Stilwell, \& Ngulube (2011) who also found that the limited number of extension officers did not allow for effective information dissemination. The second most important source of information was found to be researchers which concurred with Daniel et al. (2013), Lwoga, Stilwell, \& Ngulube (2011), Msoffe and Ngulube (2016) and Mtega, Ngoepe, \& Dube, 2016). However, in our study it was found that while many researchers provided useful information at the beginning of their research projects, once projects finished no one returned to the farmers to monitor longer term implementation and scale up of the 
knowledge gained. There is a need for researchers to work more closely with farmers as well as agricultural extension officers for effective learning, adoption of the technology and sustainability even after research projects cease. Various research findings which could have increased efficiency in agricultural productivity are not known or applied by the farmers due to poor research dissemination (Lwoga, Stilwell, \& Ngulube, 2011). Farmers have limited access to much of agricultural information from research institutions, universities and public offices despite being the target group for this information.

Farmer research networks (FRN) have been cited as an effective option of involving farmers in research for more effective uptake of knowledge (Nelson, Coe, \& Haussmann, 2016). Farmer Field Schools (FFS) have also been promoted as a practical approach of disseminating knowledge among farmers (Nelson et al., 2001). Khatam et al. (2010) reported some of the advantages of FFS to be self-confidence, skills and knowledge improvement, helping farmers in learning by doing and discouraging the use of pesticides while motivating farmers in using homemade pesticides thereby conserving the environment. These information sources were also found to be useful from other studies (Isaya, Agunga, \& Sanga, 2016; Lwoga, Stilwell, \& Ngulube, 2011; Magesa, Michael, \& Ko, 2014; Mtega, Ngoepe, \& Dube (2016)).

Agricultural training is one of the ways that could help the farmers to be better informed of new agricultural techniques and practices (Nakano, Tsusaka, Aida, \& Pede, 2018; Sjakir, Awang, Azima, Hussain \& Zaimah, 2015). The percent of farmers who had never attended any training in this study was $73 \%$ which was reasonably high compared with the findings of a similar study conducted in the Kilolo district in the Iringa region of Tanzania where $51 \%$ of respondents had never attended any training (Mwamakimbula, 2014). This requires further investigation on social and economic factors leading to poor access of the information and training opportunities among the farmers. Mwamakimbula (2014) found that of those who never attended training, 51.7\% said it was because they did not get information about the training while $40 \%$ did not know when the training events are conducted. The results of this study showed no significant difference in access to formal education or training events between men and women which contrasted with other recent reports (Mtega, Ngoepe, \& Dube, 2016; Mudege, Mdege, Abidin, \& Bhatasara, 2017; Riley, 1995). 
Farmers proposed various ways of improving bean production in the area, the most urgent being provision of education on bean production, as most of the farmers claimed to grow beans from experience without any training. Education on pest management and other inputs was also suggested by the farmers since insect pests are among the most common and visible problems affecting bean production. Pest management was very much oriented to chemical pesticide use by the calendar rather than using damage assessment and IPM principles, and without any knowledge on the environmental side effects of the chemicals. Synthetic pesticides are registered products, so farmers do not see a reason why they should not be used because they did not consider the impacts of the misuse of synthetic pesticides to the environment (Korir et al., 2015). As a result of various challenges experienced from the use of synthetic pesticides, they declared the need for education on alternative ways to manage the pests as well as safe use of various agricultural inputs. The farmers were also concerned with timely provision of the agricultural inputs as they were mostly provided too late. Among the agricultural subsidies that were provided by the government in the study area were pesticides and fertilizers. However, there is a need to rethink whether the agricultural subsidies are causing more harm than good with regard to sustainability in agriculture (Dorward, 2009). This is because the agricultural subsidies may lead farmers to overuse fertilizers and pesticides, leading to negative environmental impacts including impacts on beneficial arthropods.

\subsection{Conclusion}

Farmers in the Kilimanjaro region of Tanzania lack a fundamental understanding of the importance of biodiversity on farms and its role in pest management, and lack training around use of local and botanical pest control methods. Researchers are failing to disseminate their findings effectively to farmers, the end-users. In view of this, educating farmers about the value of natural enemies and the practise required to maintain populations of these arthropods as well as controlling insect pests and different ways of managing them is essential to support sustainable production among smallholders. There is a need to improve farmers' knowledge about agricultural landscape biodiversity for better management to support natural pest regulation. They should be trained to assess insect damage and to develop an economic threshold for the different bean pests in the region in order to reduce synthetic pesticide use. CBC should be promoted among 
smallholder farmers through appropriate knowledge provision and tools to facilitate its adoption. One of the factors leading to low levels of adoption of improved agricultural techniques is the lack of agricultural information among the farmers, which is associated with poor linkages between knowledge providing institutions and farming communities. Addressing these barriers will enable movement towards more environmentally sustainable crop production.

\section{Acknowledgements}

We gratefully acknowledge the agricultural extension officers of Moshi rural district for their tireless cooperation during the survey and training of the farmers, and the farmers themselves for participating in the project. This work was funded by McKnight Foundation projects (\#13-335 and \#17-070, http://ccrp.org/) to GMG and a Darwin Initiative project (22-021, http://www.darwininitiative.org.uk/project/22012) to PCS with further support from Charles Sturt University.

\section{Author contributions}

Gurr GM, Stevenson PC, Belmain SR, Arnold SEJ and Ndakidemi PA conceived the study. Mkenda PA, Darbyshire I and Tumbo J were involved in the study design. Mkenda P, Tumbo J and Priebe J carried out the survey. Xie G and Mkenda PA carried out the statistical analysis. Mkenda PA wrote the first draft of the manuscript. Johnson AC and other authors edited the manuscript and gave final approval for publication.

\section{Conflict of interest}

The authors declare that there is no any conflict of interest.

\section{Reference}

Abate, T., \& Ampofo, J. K. O. (1996). Insect pests of beans in Africa: their ecology and management. Annual Review of Entomology, 41, 45-73.

Adam, R. I., Sindi, K., \& Badstue, L. (2015). Farmers' knowledge, perceptions and management of diseases affecting sweet potatoes in the Lake Victoria Zone 
region,

10.1016/j.cropro.2015.02.010.

Adhiguru, P., Birthal, P. S., \& Kumar, B. G. (2009). Strengthen pluralistic agricultural information delivery systems in India. Agricultural Economics Research Review, 22, 71- 79 .

Aina, L. O. (2006). Information provision to farmers in Africa: The library extension service linkage. World Library Information Congress, 72, 1-7.

Amoabeng, B. W., Gurr, G. M., Gitau, C. W. \& Stevenson, P. C. (2013). Cost: benefit analysis of botanical insecticide use in cabbage: Implications for smallholder farmers in developing countries. Crop Protection, 57, 71-76. Doi:10.1016/j.cropro.2013.11.019.

Amoabeng, B., Asare, K., Asare, O., Mochiah, M., Adama, I., Fening, K. \& Gurr, G. M. (2017). Pesticides use and misuse in cabbage Brassica oleracea var. capitata L. (Cruciferae) production in Ghana: The influence of farmer education and training. Journal of Agriculture and Ecology Research International, 10, 1-9. Doi: 10.9734/jaeri/2017/30128.

Aquilino, K. M., Bradley, J. C., \& Anthony, R. I. (2005). Reciprocal effects of host plant and natural enemy diversity on herbivore suppression: An empirical study of a model tritrophic system. OIKOS, 2, 275-82. Doi: 10.1111/j.00301299.2005.13418.x.

Ashburner, J. \& Friedrich, T. (2001). Improving Handling of Pesticides Application Equipment for the Safety of Applicators. Pesticide Management in West Africa Newsletter no. 2. FAO/Economic Community of West African States, Accra, Ghana, pp. 9-11.

Banjo, A.D., Lawal, O.A., Fapojuwo, O.E. \& Songonuga, E. A. (2003). Farmers' knowledge and perception of horticultural insect pest problems in southwestern Nigeria. African Journal of Biotechnology, 2(11), 434-437.

Belmain, S.R., Haggar, J., Holt, J. \& Stevenson, P.C. (2013). Managing legume pests in sub-Saharan Africa: Challenges and prospects for improving food security and nutrition through agro- ecological intensification. Chatham Maritime (United Kingdom): Natural Resources Institute, University of Greenwich. 34p. 
Blodgett, S., Denke, P. M., \& Knerr, V. (2010). Blister beetles of Montana. Montana State University Extension, 1-4.

Chancellor, T. C., Priebe, J. S., \& Mkenda, P. A. (2019). Crowdsourcing field observations from smallholder farmers in Tanzania using interactive voice response. Outlooks on Pest Management,30(3), 104-110. DOI: 10.1564/v30_jun_02.

Daniel, E., Bastiaans, L., Rodenburg, J., Center, A. R., Schut, M., \& Mohamed, J. K. (2013). Assessment of agricultural extension services in Tanzania: A case study of Kyela, Songea Rural and Morogoro Rural Districts. Internship Report, Plant Science, 1-45.

Dorward, A. (2009). Rethinking Agricultural Input Subsidy Programmes in a Changing World [Prepared for the Trade and Markets Division, Food and Agriculture Organization of the United Nations], Centre for Development, Environment and Policy, 1-50.

Eilenberg, J., Hajek, A. \& Lomer, C. (2001). Suggestions for unifying the terminology in biological control. Biocontrol, 46, 387-400.

Elly, T. \& Silayo, E. (2013). Agricultural information needs and sources of the rural farmers in Tanzania: A case of Iringa rural district. Library Review, 62(8/9), 547566.

Grzywacz, D., Stevenson, P. C., Mushobozi, W. L., Belmain, S. \& Wilson, K. (2014). The use of indigenous ecological resources for pest control in Africa. Food Security, 6, 71-86. DOI 10.1007/s12571-013-0313-5.

Halimatunsadiah, A. B., Mazlan, N., Omar, D., \& Kamarulzaman, N. H. (2016). Application of pesticide in pest management: The case of lowland vegetable growers. International Food Research Journal, 23(1), 85-94. 
Heitala-Koivu R., Lankoski J., \& Tarmi S. (2004). Loss of biodiversity and its social cost in an agricultural landscape. Agriculture, Ecosystems and Environment, 103, 7583. https://doi.org/10.1016/j.agee.2003.10.015.

Hemp, A. (2006). Continuum or zonation? Altitudinal gradients in the forest vegetation of Mt. Kilimanjaro. Plant Ecology, 184, 27-42. DOI 10.1007/s11258-005-90494.

Isaya, E. L., Agunga, R., \& Sanga, C. A. (2016). Sources of agricultural information for women farmers in Tanzania. Information Development, 1-13. DOI: $10.1177 / 0266666916675016$.

Kariathi, V., Kassim, N., \& Kimanya, M. (2016). Pesticide exposure from fresh tomatoes and its relationship with pesticide application practices in Meru district. Cogent Food and Agriculture, 2, 1196808. Doi.org/10.1080/23311932.2016.1196808.

Khatam, A., Muhammad, S., Chaudhry, K. M., Mann, A. H., Haq, I., Khan, Z. U., \& Amin, H. (2010). Strengths and weaknesses of Farmers' Field Schools approach as perceived by farmers. Sarhad Journal of Agriculture, 26(26), 685-688.

Korir, J. K., Affognon, H. D., Ritho, C. N., Kingori, W. S., Irungu, P., Mohamed, S. A., \& Ekesi, S. (2015). Grower adoption of an integrated pest management package for management of mango-infesting fruit flies (Diptera: Tephritidae) in Embu, Kenya.International Journal of Tropical Insect Science, 35, 80-89. Doi:10.1017/S1742758415000077.

Kremen, C., \& Miles, A. (2012). Ecosystem services in biologically diversified versus conventional farming systems: benefits, externalities, and trade-offs. Ecology and Society, 17(4), 40. Doi:10.5751/ES-05035-170440.

Laizer, H. C., Chacha, M. N., \& Ndakidemi, P. A. (2019). Farmers' Knowledge, Perceptions and Practices in Managing Weeds and Insect Pests of Common Bean in Northern Tanzania. Sustainability, 11(15), 4076. Doi:10.3390/su11154076.

Landis, D. A., Wratten, S. D., \& Gurr, G. M. (2000). Habitat management to conserve natural enemies of arthropod pests in agriculture. Annual Review of Entomology, $45,175-201$. 
Lebesa, L. N., Khan, Z. R., Krüger, K., Bruce, T. J., Hassanali, A., \& Pickett, J. A. (2012). Farmers' knowledge and perceptions of blister beetles, Hycleus spp. (Coleoptera: Meloidae), as pest herbivores of Desmodium legumes in western Kenya. International Journal of Pest Management,58(2), 165-174. Doi:10.1080/09670874.2012.673032.

Lekei, E. E., Ngowi, A. V., \& London, L. (2014). Farmers' knowledge, practices and injuries associated with pesticide exposure in rural farming villages in Tanzania. BMC Public Health, 14, 389. Doi: 10.1186/1471-2458-14-389.

Lwoga, T. E., Stilwell, C., \& Ngulube, P. (2011). Access and use of agricultural information and knowledge in Tanzania. Library Review, 60(5), 383-395. Doi: 10.1108/00242531111135263.

Magesa, M. M., Michael, K., \& Ko, J. (2014). Access to Agricultural Market Information by Rural Farmers in Tanzania. International Journal of Information and Communication Technology Research, 4, 264-273.

Mahugija, J. A. M., Chibura, P. E., \& Lugwisha, E. H. J. (2018). Residues of pesticides and metabolites in chicken kidney, liver and muscle samples from poultry farms in Dar es Salaam and Pwani, Tanzania. Chemosphere, 193, 869-874.

Margni, M., Rossier, D., Crettaz, P., \& Jolliet, O. (2002). Life cycle impact assessment of pesticides on human health and ecosystems. Agriculture Ecosystems and Environment, 93(1), 379-392.

Martin, E. A., Reineking, B., Seo, B., \& Steffan-Dewenter, I. (2013). Natural enemy interactions constrain pest control in complex agricultural landscapes. Proceedings of the National Academy of Sciences of the United States of America, 110, 5534-39.

Matthews, G., Wiles, T., \& Baleguel, P. (2003). A survey of pesticide application in Cameroon. Crop Protection, 22(5), 707-714. Doi: 10.1016/S02612194(03)00008-5.

Meijer, S. S., Catacutan, D., Ajayi, O. C., Sileshi, G. W., \& Nieuwenhuis, M. (2015). The role of knowledge, attitudes and perceptions in the uptake of agricultural and agroforestry innovations among smallholder farmers in sub-Saharan Africa. International Journal of Agricultural Sustainability, 13(1), 40-54. 
Mkenda, P. A., Ndakidemi, P. A., Stevenson, P. C., Arnold, S. E. J., Belmain, S. R., Chidege, M. \& Gurr, G. M. (2019). Field margin vegetation in Tropical African bean systems harbours diverse natural enemies for biological pest control in adjacent crops. Sustainability, 11, 6399. Doi: 10.3390/su11226399.

Mkenda, P. A., Mwanauta, R., Stevenson, P. C., Ndakidemi, P., Mtei, K., \& Belmain, S. R., (2015). Extracts from field margin weeds provide economically viable and environmentally benign pest control compared to synthetic pesticides. PloS one 10, e0143530.

Mkenda, P. A., Ndakidemi, P.A., \& Mbega, E. (2017). Potentials and challenges of natural pest control for sustainable legume production in Africa. International Journal of Biosciences, 10(3), 357-373. Doi:10.12692/ijb/10.3.357-373.

Mkindi, A., Mpumi, N., Tembo, Y., Stevenson, P. C., Ndakidemi, P. A., Mtei, K. \& Belmain, S. R. (2017). Invasive weeds with pesticidal properties as potential new crops. Industrial Crops and Products. 110: 113-122. Msoffe, G. E., \& Ngulube, P. (2016). Information needs of poultry farmers in selected rural areas of Tanzania. Information Development, 32, 1085-1096. DOI: $10.1177 / 0266666915587749$.

Mtega, W. P., Ngoepe, M., \& Dube, L. (2016). Factors influencing access to agricultural knowledge: the case of smallholder rice farmers in the Kilombero district of Tanzania: original research. South African Journal of Information Management, 18(1), a679. Doi:10.4102/sajim.v18i1.679.

Mudege, N. N., Mdege, N., Abidin P. E., \& Bhatasara S. (2017). The role of gender norms in access to agricultural training in Chikwawa and Phalombe, Malawi. Gender, Place and Culture 24, 12, 1689-1710. DOI: 10.1080/0966369X.2017.1383363.

Mulangu, F., \& Kraybill, D., 2013. In: Mann, S. (Ed.), Climate Change and the Future of Mountain Farming on Mt. Kilimanjaro. Springer Geography, Springer-Verlag Berlin Heidelberg. Doi: 10.1007/978-3-642-33584-6.

Mwamakimbula, A. M. (2014). Assessment of the factors impacting agricultural extension training programs in Tanzania: a descriptive study. A thesis submitted to the graduate faculty in partial fulfilment of the requirements for the degree of Master of Science, Iowa State University, 1-98.

Mwang'ombe, A. W., Thiongo, G., Olubayo, F. \& Kiprop, E. (2007). Occurrence of root rot disease of common bean (Phaseolus vulgaris L.) in association with bean stem 
maggot (Ophyiomia sp.) in Embu District, Kenya. Plant Pathology Journal, 6(2), 141-146. DOI: 10.3923/ppj.2007.141.146.

Naing, L., Winn, T., \& Rusli, B. N. (2006). Practical issues in calculating the sample size for prevalence studies. Archives of orofacial Sciences, 1, 9-14.

Nakano, Y., Tsusaka, T. W., Aida, T., \& Pede, V. O. (2018). Is farmer-to-farmer extension effective? The impact of training on technology adoption and rice farming productivity in Tanzania. World Development, 105, 336-351. Doi:10.1016/j.worlddev.2017.12.013

Nelson, R., Coe, R., \& Haussmann, B.I. (2016). Farmer Research Networks as a strategy for Matching Diverse Options and Contexts in Smallholder Agriculture. Experimental Agriculture, 1-20. Doi:10.1017/S0014479716000454.

Nelson, R. J., Orrego, R., Ortiz, O., Mundt, M., Fredix, M. \& Vien, N.V. (2001). Working with Resource-poor Farmers to Mange Plant Diseases. Plant Disease, 85, 684695. Doi:10.1094/PDIS.2001.85.7.684.

Ngowi, A. V., Maeda, D. N., Wesseling, C., Partanen, T. J., Sanga, M. P., \& Mbise, G. (2001). Pesticide-handling practices in agriculture in Tanzania: Observational data from 27 coffee and cotton farms. International journal of occupational and environmental health, 7, 326-332. Doi:10.1179/107735201800339218.

Ngowi, A. V. F., Mbise, T. J., Ijani, A. S. M., London, L., \& Ajayi, O. C. (2007). Pesticides use by smallholder farmers in vegetable production in Northern Tanzania. Crop Protection, 26(11), 1617.

Nguyen, T. P. L., Seddaiu, G., \& Roggero, P. P. (2014). Hybrid knowledge for understanding complex agri-environmental issues: Nitrate pollution in Italy. International Journal of Agricultural Sustainability, 12(2), 164-182. Doi: 10.1080/14735903.2013.825995.

Ntow, W. J., Gijzen, H. J., Kelderman, P., \& Drechsel, P. (2006). Farmer perceptions and pesticide use practices in vegetable production in Ghana. Pest Management Science, 62(4), 356-365. DOI: 10.1002/ps.1178. 
Olajide, B. R. (2011). Assessment of farmers' access to agricultural information on selected food crops in Iddo District of Oyo State, Nigeria. Journal of Agricultural \& Food Information, 12(3-4), 354-363. Doi: 10.1080/10496505.2011.609434.

Olejnik, S. F. (1984). Planning educational research: Determining the necessary sample size. The Journal of Experimental Education,53(1), 40-48. Doi:10.1080/00220973.1984.10806360

Pabst, H., Kühnel, A. \& Kuzyakov, Y. (2013). Effect of land-use and elevation on microbial biomass and water extractable carbon in soils of Mt. Kilimanjaro ecosystems. Applied Soil Ecology, 67, 10-19. Doi: 10.1016/j.apsoil.2013.02.006.

Palm, C., Blanco-Canqui, H., DeClerck, F., Gatere, L. \& Grace, P. (2014). Conservation agriculture and ecosystem services: An overview. Agriculture Ecosystems and Environment, 187, 87-105. DOI: 10.1016/j.agee.2013.10.010.

Riley, P.J. (1995). Gender issues and the training is agricultural extensionists in Malawi. Agriculture and Human Values, 12, 31-38. Doi:10.1007/BF02218072.

Ronald, B., Dulle, F., \& Honesta, N. (2014). Assessment of the Information Needs of Rice Farmers in Tanzania: A Case Study of Kilombero District, Morogoro. Library Philosophy and Practice, 1-34.

Shannag, H. K., \& Ababneh, J.A. (2007). Biometry and responses of faba bean varieties to black bean aphid, Aphis fabae Scopoli. American-Eurasian Journal of Agricultural and Environmental Sciences, 2, 328-334.

Sibanda, T., Dobson, H. M., Cooper, J. F., Manyangarirwa, W., \& Chiimba, W. (2000). Pest management challenges for smallholder vegetable farmers in Zimbabwe. Crop Protection, 19(8), 807-815. Doi: 10.1016/S02612194(00)00108-3.

Siyao, P. O. (2012). Barriers in accessing agricultural information in Tanzania with a gender perspective: the case study of small-scale sugar cane growers in Kilombero District. Electronic Journal of Information Systems in Developing Countries, 51(6), 1-19. 
Sjakir, M., Awang, A. H., Azima, A. M., Hussain, M. Y., \& Zaimah, R. (2015). Learning and Technology Adoption Impacts on Farmer's Productivity. Mediterranean Journal of Social Sciences, 6(4), 126. Doi: 10.5901/mjss.2015.v6n4s3p126.

Team, R. C. (2017). R: A Language and Environment for Statistical Computing (version 3.4.2). R foundation for statistical computing, Vienna, Austria.

Tosi, S., Costa, C., Vesco, U., Quaglia, G., \& Guido, G. (2018). A 3-year survey of Italian honey bee-collected pollen reveals widespread contamination by agricultural pesticides. Science of the Total Environment, 615, 208-218. Doi: 10.1016/j.scitotenv.2017.09.226.

Williamson, S., Ball, A., \& Pretty, J. (2008). Trends in pesticide use and drivers for safer pest management in four African countries. Crop Protection, 27, 1327-1334. Doi: 10.1016/j.cropro.2008.04.006.

Wilson, C., \& Tisdell, C. (2001). Why farmers continue to use pesticides despite environmental, health and sustainability costs. Ecological Economics, 39(3), 449462.

Wyckhuys, K.A.G., Lu, Y., Morales, H., Vazquez, L.L., Legaspi, J.C., Eliopoulos, P.A., \& Hernandez, L.M. (2013). Current status and potential of conservation biological control for agriculture in the developing world. Biological Control, 65, 152 - 167. 